Original Article

\title{
Prevalence and Characteristics of Stress Among Bereaved Parents After the Death of Their Under-Five Children in The Urban Slums of Karachi, Pakistan Muhammad Bilal Siddiquil,2, Shamoon Noushad ${ }^{4}$, Chiu Wan $\mathrm{Ng}^{5}$, Wah Yun Low ${ }^{6}$ \& Sadaf Ahmed ${ }^{3,4}$ \\ I"Centre of Maternal and Child Health Research" (CoMCHR), AEIRC \\ ${ }^{2}$ Hamdard University, Department of Community Health Sciences, Karachi Pakistan. \\ ${ }^{3}$ Psychophysiology research lab, Physiology Department, University of Karachi, Pakistan. \\ ${ }^{4}$ Advanced Educational Institute of Institute \& Research Centre. \\ ${ }^{5}$ Department of Social and Preventive Medicine, University of Malaya, Kuala Lumpur, Malaysia. \\ ${ }^{6}$ Health Research Development Unit, Faculty of Medicine, University of Malaya. \\ Corresponding Author: drbilals@gmail.com
}

\begin{abstract}
Introduction To understand the prevalence of stress and identifying the prevalence of different differentials of stress among bereaved parents of died under-five children is of utmost importance. This paper is based on the data from Karachi VASA under-five mortality study. The cases of this study are bereaved parents of deceased under-five children belonging to randomly selected 12 slums of Karachi city. Methodology A total of 321 parents excluded out form enrolment in VASA study were undergone stress assessment using Sadaf Stress Scale (SSS). It was found that $100 \%$ of them were truly stressed in one form or the other and the distribution is equally affecting all the slums (with slight variations). Females were found highly stressed (72\%) than males $(28 \%)$. The most prevalent types of stress identified were emotional $(67 \%)$, traumatic $(17.2 \%)$ and mental stress $(7 \%)$. Out of all the stressed parents, a high proportion belongs to highest severity. The highest prevalence of the severity of traumatic stress shows that the large proportion of stressed parents have gone to Post-Traumatic Stress Disorder (PTSD), especially among mothers. Conclusion The results are quiet disturbing. The data shows that there is a high prevalence of traumatic, physical and emotional stress among bereaved parents (especially mothers) of deceased children. The prevalence of traumatic stress and its severity shows that a high proportion of stressed parents have gone to PTSD, which again have a huge impact on the overall mental health of the affected and the close family members.
\end{abstract}

\section{Keywords}

Stress, Post-Traumatic Stress Disorder, Child Mortality, Parents, Mental Health.

\section{Introduction}

Pakistan stands third among the top five countries that carries almost $66 \%$ of the current global under-five mortality burden (Mehnaz, 2011; PDHS, 2012-2013). The rest are India, Nigeria, China and Democratic Republic of Congo (UNICEF-
Report-2015). Karachi, being the highly populous metropolitan cities of Pakistan, has multitude of factors affecting access to the health services to the needy population (Shaikh, 2016; Uzma Afzal, 2013). Almost $62 \%$ of Karachi's population is residing in slums (Shaikh, 2016). These slums have 
high child mortality rate across the city (PDHS, 2012-2013). Although several segregated attempts show dispersed estimates of the child mortality burden from such slums, no updated and reliable data exist that clearly depicts the overall child mortality burden among such urban slums (Ayaz \& Saleem, 2010; M B Siddiqui, 2016). The death of the child is one of the leading setback and trauma for the family, especially for the parents (Morris, GabertQuillen, Friebert, Carst, \& Delahanty, 2016). Whether, it is miscarriage, stillbirth, or live birth; the trauma has always been an excruciating feeling that deeply influences the family (Hawthorne, Youngblut, \& Brooten, 2016; Turton, Hughes, Evans, \& Fainman, 2001).

Depression and stress among pregnant mothers is an integral part of the pregnancy (Rai, Pathak, \& Sharma, 2015). Postpartum blues counts for majority of the depressive attacks, which subsides overtime (O'Hara \& Swain, 1996). Postnatal depression continues to almost 4-12 weeks; however, if this depression combines with death of any close family member or the child, the grief may continue as stress (O'Hara \& Swain, 1996). However, if the symptoms of such severe grief gets prolonged, unresolved and continued, then chronic stress may lead to the condition of post-traumatic stress disorder (PTSD) (Ahmed \& Noushad, 2013). Parents, if affected with stress and/PTSD may influence the mental health of themselves and of immediate family members (Morris et al., 2016; Stiffler, Cullen, Stephenson, Luna, \& Hartman, 2016). There are several of the different types of stress. Since, a huge population of the Karachi city is residing in slums, where the child mortality rate is high, there is a dire need to identify the level of event related stress (related to the death event of their child) among parents and specific interventions need to be tested to alleviate it.

To reflect the prevalence of emotional trauma and traumatic stress, faced by the bereaved parents after the deaths of their under-five children, we are sharing the results, which were gathered from the Karachi VASA (Verbal Autopsy-Social Autopsy) under-five mortality enquiry, conducted in Karachi slums. No work has been done to identify the prevalence, characteristics and severity of the different stresses among the bereaved parents of deceased under-five children in all the urban slums of Karachi using Sadaf Stress Scale (SSS) (Shamoon Noushad \& Ahmed, 2013), which is a validated tool for Pakistani population to identify and quantifying different types of stresses. We endorse that the results are quiet disturbing and need a special attention to focus and alleviate the level of stress among such bereaved parents in the very slums of Karachi, which carries huge proportion of the city's population.

\section{Methodology}

The data of this paper belongs to Karachi VASA study 2015-16, which is currently being conducted in Karachi slums (Table-1). The VASA study recruited households where a recent under-five death (within one year of death of the under-five) occurred. After identifying deaths, a pre-survey household visit (PSHV) was conducted to exclude out parents with stress. One to one interview and use of SSS was used to calculate the level of stress among all the parents whose under-five children were died during the last year.

The PSHV principally excluded the stressed and non-stressed parents by using SSS. Overall, from PSHV, the excluded out cases included three categories: (1) those parents 
who were screened out (by the Psychologist) with a potentiality of getting emotional distress during interview (data collection phase) using SSS; (2) those who have been relocated after the death of their children; and (3) who did not give the consent due to any other reason apart from getting emotionally charged and (see Figure-1). Figure-2 shows percentages of recruited VS excluded out parents in VASA study. The sample size of the VASA study was 400 households where a history of recent deaths due to illness (and excluding those households where under-five children died due to accidents).

The sample size was captured from all the deaths identified. The excluded out who were labelled by the psychologist as being potential of undergoing emotional distress are the cases of this research paper (see Figure-2). The process of screening of such emotionally disturbed parents involved one to one in-depth interview with the psychiatrist during Pre-Survey Household visits and assessment of their stress level by using SSS (Shamoon Noushad \& Ahmed, 2013), which was established to evaluate and measure the stress level by recording major signs and symptoms using 95 items divided into seven subscales, each representing a type of stress (Physical, psychosocial, mental, Nutritional, traumatic, emotional and chemical). The SSS is a validated stress scale for Pakistani Population.

\section{Results}

Out of the randomly selected 12 slums, average of $50.8 \%(41.5 \%-56.6 \%)$ of the total excluded out parents were found stressed during the initial screening interviews (PSHV) by psychologist. The rest of $49.2 \%$ belongs to other categories of exclusion i.e. those who refused to be study subjects, and those who have been let recently (after the death of their child but before the PSHVs).

Figure-3 shows percentages of stressed patients in 12 slums. The percentage of stressed patients is on average $50.8 \%$ out of the total excluded out (Figure-3). Figure-3 shows that a majority of emotionally distressed parents belongs to Hazara colony (56.3\%), Shireen Jinnah Colony (56.6\%) and Safora goth $(56.5 \%)$. The least is in Landhi slums $(41.5 \%)$. Almost two thirds of the stressed parents were mothers across all the slums (Figure-4).

\section{Differentials of Stress}

Prevalence of different types of stresses were identified using Sadaf Stress scale. The scale consists of 95 questions covering seven different types of stresses. Out of seven different types of stresses, Emotional (66.6\%), Traumatic (17.2\%) and Mental stress $(6.9 \%)$, have been found to be the most commonly encountered types of stresses among the cases (Figure-5). Emotional and traumatic stress were found highly prevalent (two third) among females. Figure-6 \& 7 shows the distribution of Emotional and Traumatic stresses among different slums along with the male to female distribution.

\section{Severity assessment of Emotional,} Traumatic and Physical stress from SSS: Using Sadaf Stress Scale, the cases were assessed based on the severity of the three most prevalent types of stresses, and found out that the cases have been severely affected by these three types of stresses. Since the emotional stress was found most prevalent and the prevalence of its severity is also quiet high (88\%), it depicts that its affected ones were severely affected. 
Figure-1: Distribution of dropped out parents in VASA study

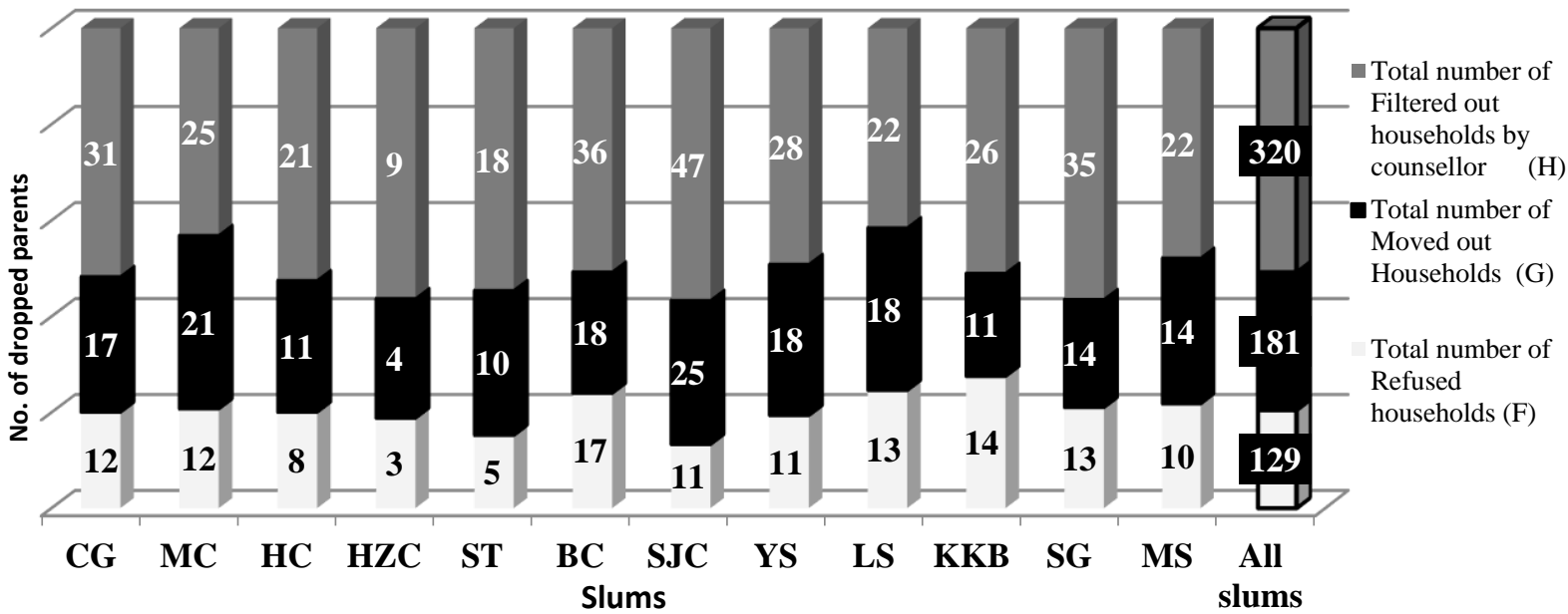

Figure-2: Percentage distribution of recruited VS dropped out parents in VASA study

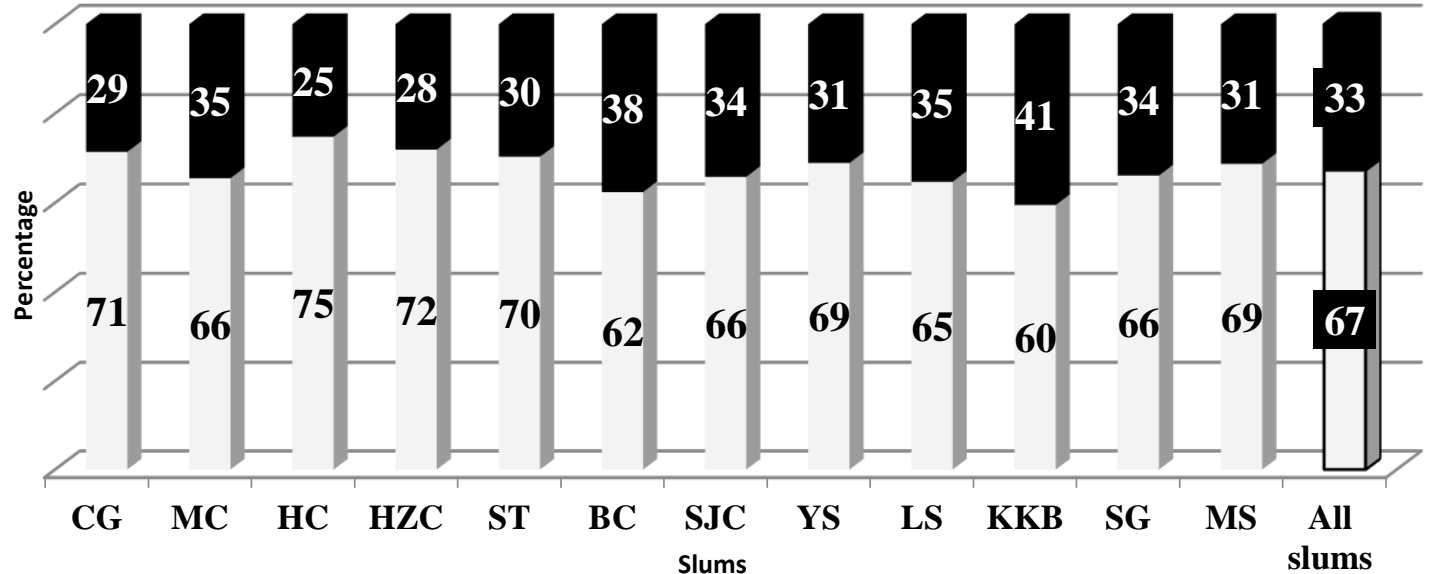

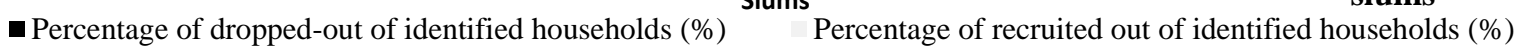

Figure-3: Proportion of Emotional distress cases out of droped out cases

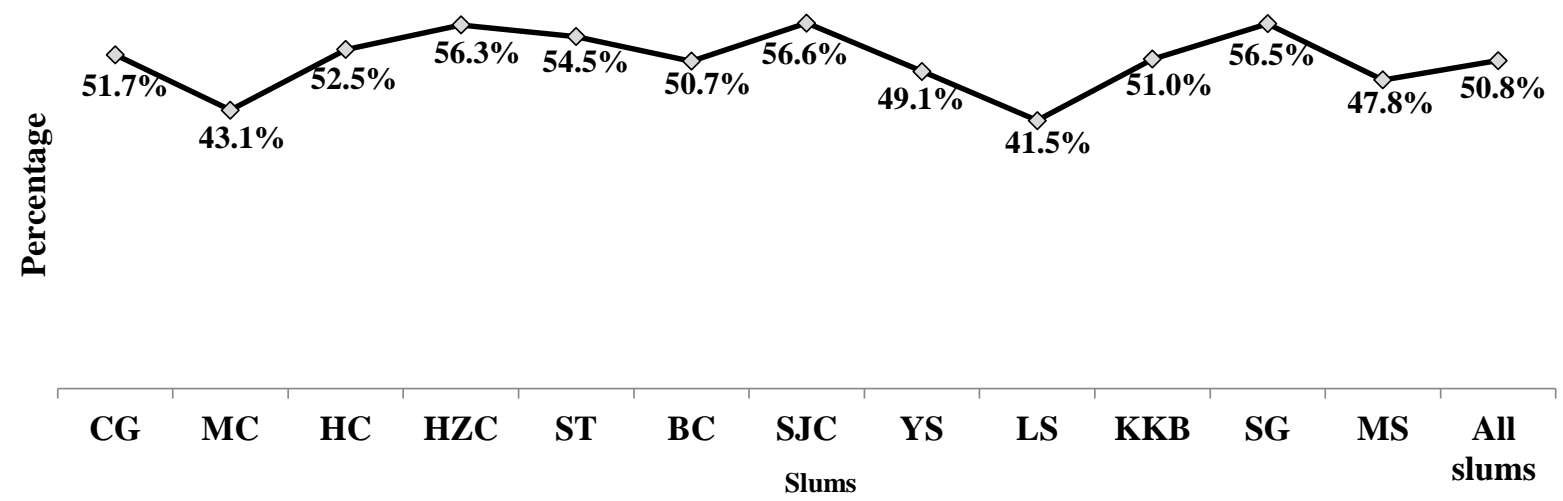


Figure-4: Gender distribution of stress among slums

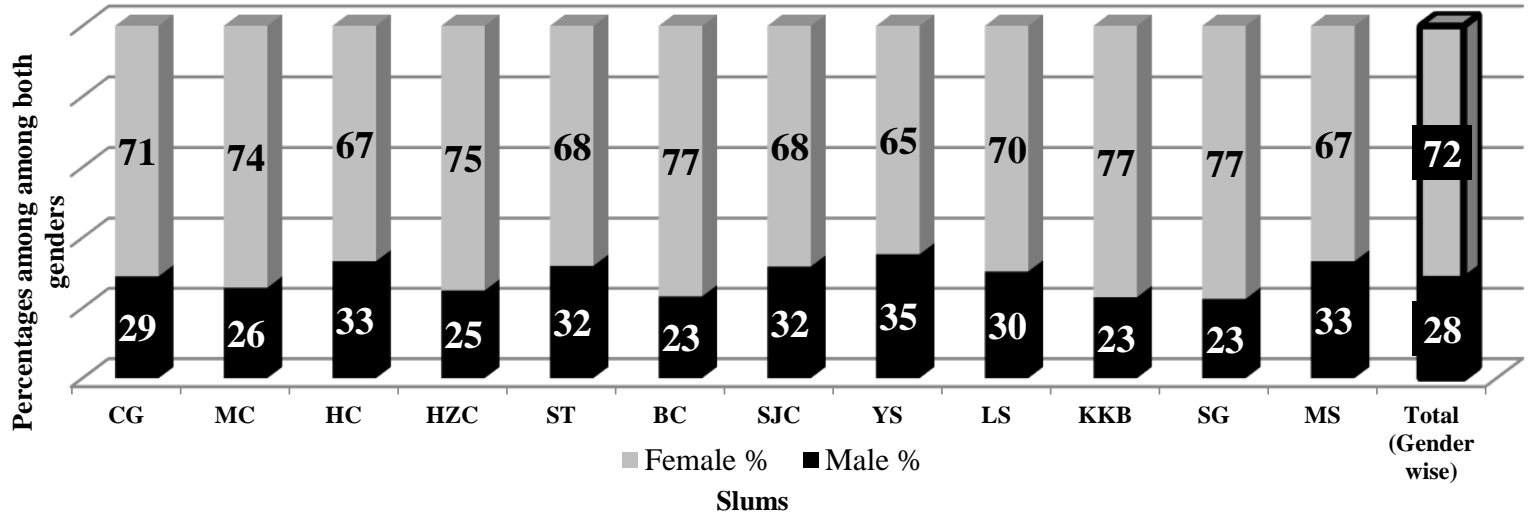

Figure-5: Percentages of stresses among cases

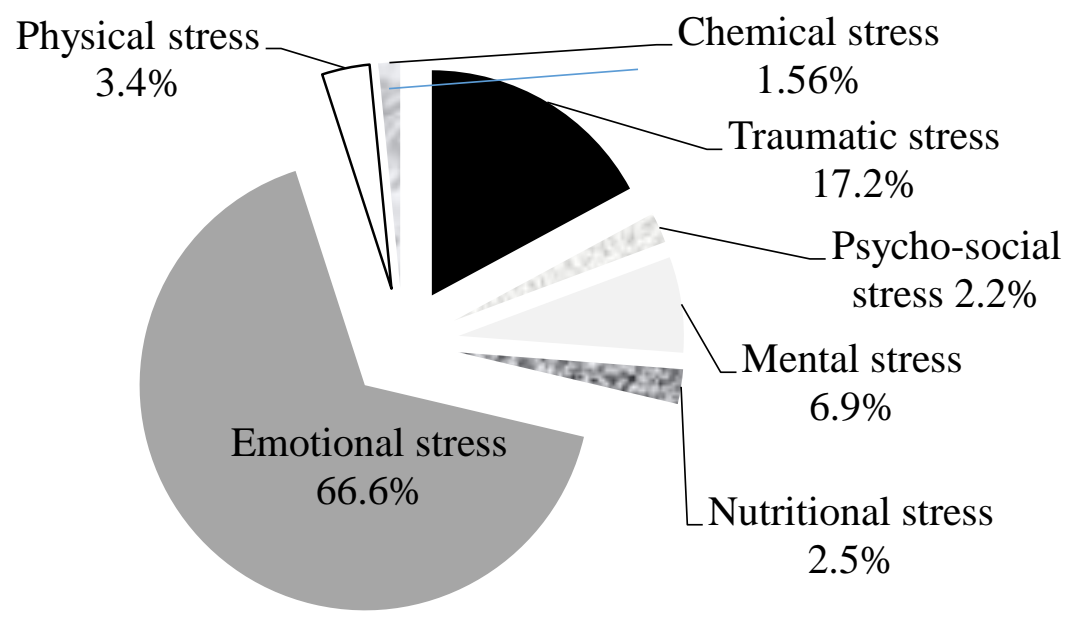

Figure-6: Traumatic stress among slums

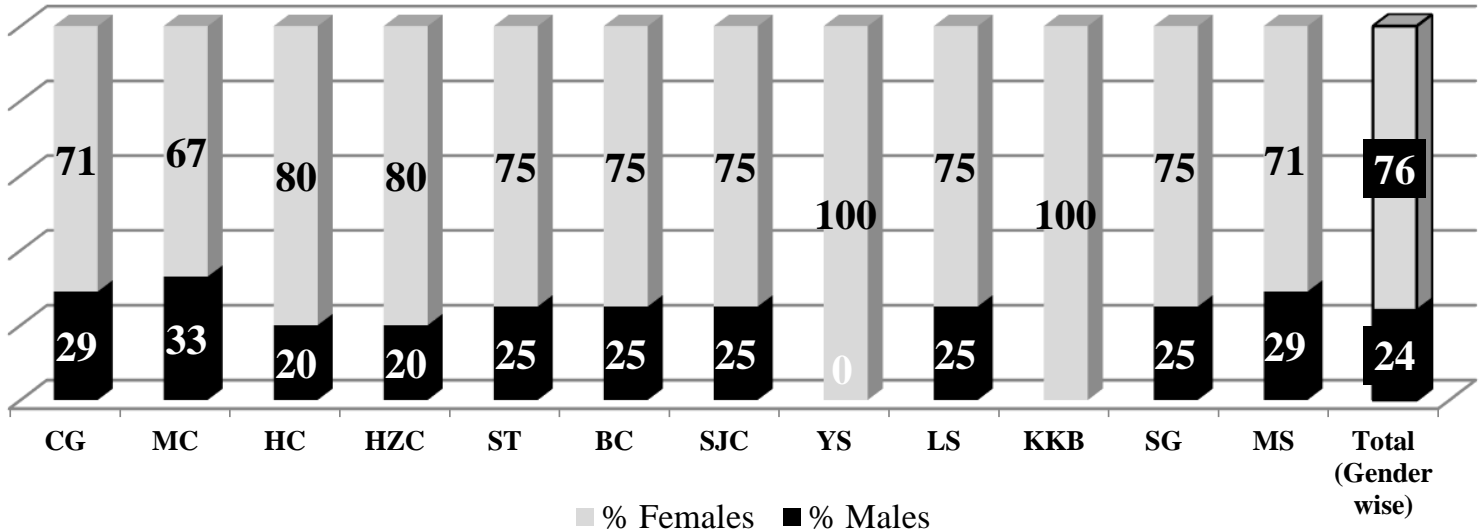


Figure-7: Emotional Stress among slums

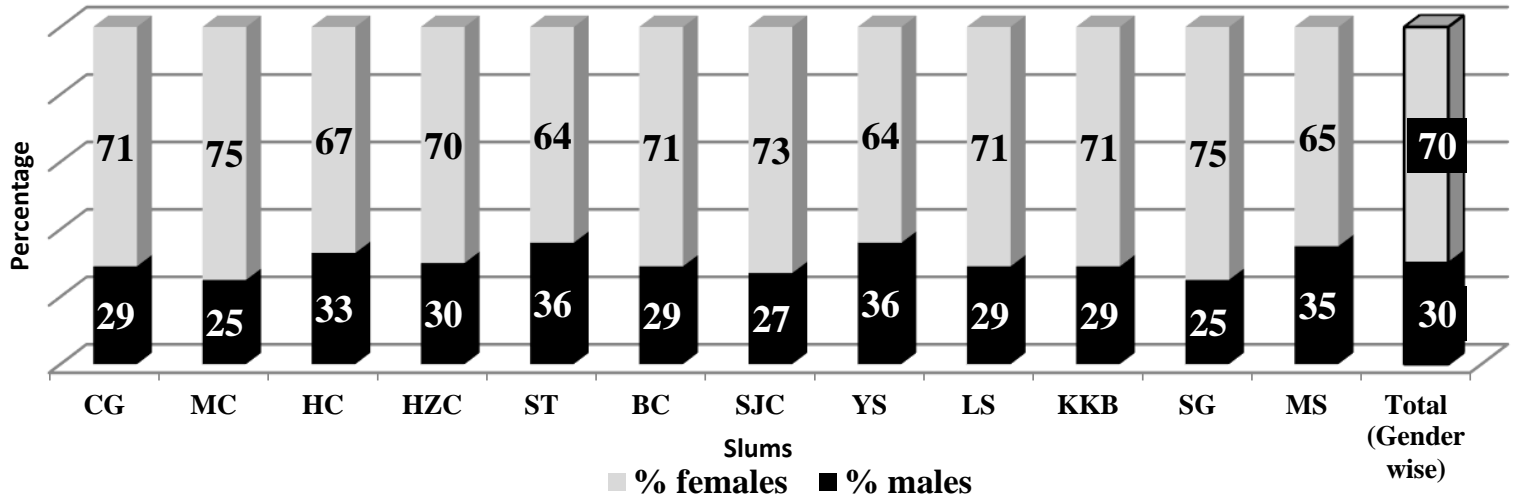

Figure-8: Severity Prevalence of Emotional stress

Mildly affected $04 \%$

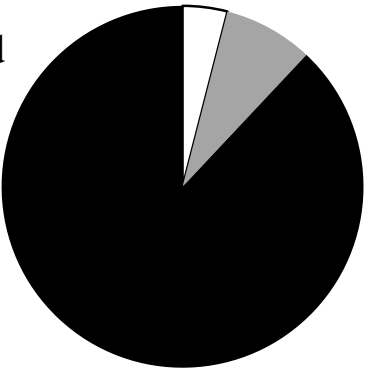

Moderately affected $8 \%$

Severly affected $88 \%$

Figure-9: Severity Prevalence of Traumatic stress

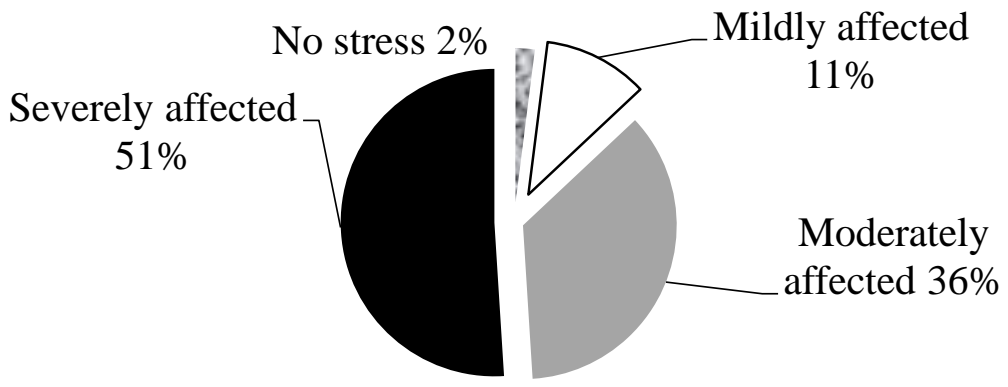

Figure-10: Severity Prevalence of Mental stress

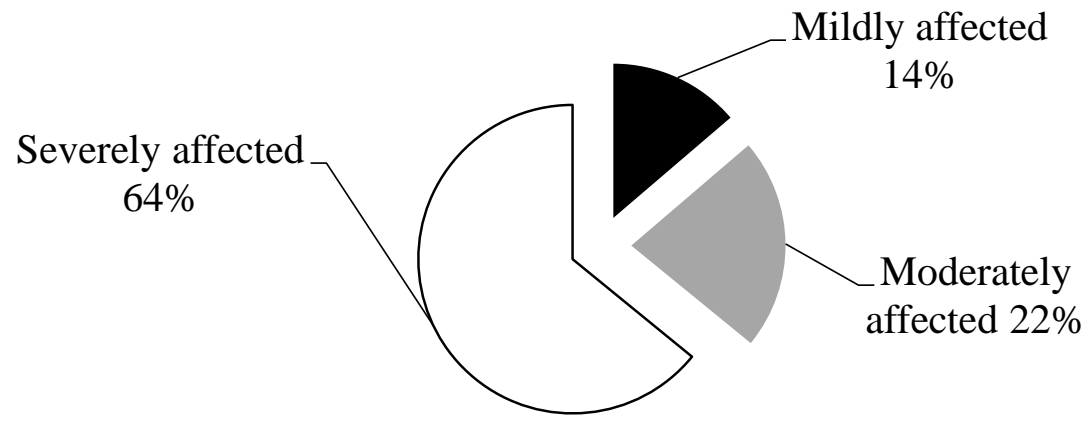




\section{Discussion}

Slums holds almost two third of Karachi's population. Child mortality is one of the menaces of these urban slums. Due to high under-five mortality in such slums, mental health status of the bereaved parents may be compromised. There is a need to evaluate the mental health status of the bereaved parents across all the slums of the city related to the death of their children. Data shows that stress is highly prevalent among the bereaved parents of the slums. While discussing the death incidents (which occurred within the duration of one year from the interview), parents were found to be traumatic, mental and emotionally stressed at the time of interview. Emotional stress was found to be highly prevalent among other stress types and the affected ones were severely affected. Mothers showed signs and symptoms with severe strengths, showing that they have not forgotten the death event completely.

Not only this, but the event is still lingering in their recall, which bring them in a state of stress. A large proportion (almost $80 \%$ ) of these parents showed that they have they still receives nightmares and recall of the event. The high prevalence of severely affected traumatic, mental and emotional stress shows that the parents have gone to the limits of PTSD. There is a huge concern that when the mother is severely affected with traumatic stress and more specifically with PTSD, the mental health of the whole family is indirectly affected. We did not use any other scale to measure the PTSD score and relied on the SSS scoring. Future studies should focus on the calculation of PTSD to see the severity of PTSD symptoms. Further investigations are needed which should identify the impact of all the stresses and PTSD on the overall health, especially the mental health of the affected as well as family members. More research is needed to suggest the interventions focusing alleviating the cases from such traumas and how to overcome such huge grief among the affected ones.

\section{Conclusion}

The results are very disturbing. The bereaved parents of slums (which carries two thirds of the Karachi's population) are severely affected with stress relating to the death of their children, and their traumatic stress has now progressed towards PostTraumatic Stress Disorder (PTSD). The stress is highly prevalent among mothers as compared to fathers.

\section{Conflict of Interest}

All the authors disclose that there are no competing interests in the preparation of this article.

\section{Acknowledgment}

we want to acknowledge all the researchers and healthcare professionals (along with all the funding agencies) who strive and give their efforts in improving women and child survival of the developing countries. Their untiring efforts should be complemented by a strong governmental support to bring a positive change.

\section{References}

- Ahmed, S., \& Noushad, S. (2013). Sorts and sources of stress in Pakistan; a comprehensive outlook. International Journal of Endorsing Health Science Research, 1(1), 4-8.

- Ayaz, A., \& Saleem, S. (2010). Neonatal Mortality and Prevalence of Practices for Newborn Care in a Squatter Settlement of Karachi, Pakistan: A Cross-Sectional Study. PLoS ONE, 5(11).

- Hawthorne, D. M., Youngblut, J. M., \& Brooten, D. (2016). Parent Spirituality, 
Grief, and Mental Health at 1 and 3 Months After Their Infant's/Child's Death in an Intensive Care Unit. Journal of Pediatric Nursing, 31(1), 73-80. doi:http://dx.doi.org/10.1016/j.pedn.2015 .07 .008

- M B Siddiqui, C. W. N., Wah Yun Low. (2016). Social Autopsy is a dire need for investigating child mortality in Pakistan. International Journal of Endorsing Health Science Research, 4(2). Retrieved from http://aeirc-edu.com/wpcontent/uploads/Download-full-Paper12.pdf

- Mehnaz, A. (2011). State of children in Pakistan - confronting reality. Journal of the Pakistan Medical Association, 61(6), 518-519.

- Morris, A. T., Gabert-Quillen, C., Friebert, S., Carst, N., \& Delahanty, D. L. (2016). The Indirect Effect of Positive Parenting on the Relationship Between Parent and Sibling Bereavement Outcomes After the Death of a Child. Journal of Pain and Symptom Management, 51(1), 60-70. doi:http://dx.doi.org/10.1016/j.jpainsym man.2015.08.011

- O'Hara, M. W., \& Swain, A. M. (1996). Rates and risk of postpartum depression - a meta-analysis. International Review of Psychiatry, 8(1), 37-54. doi:10.3109/09540269609037816

- PDHS. (2012-2013). Pakistan Demographic Health Survey 2012-2013.

- Rai, S., Pathak, A., \& Sharma, I. (2015). Postpartum psychiatric disorders: Early diagnosis and management. Indian Journal of Psychiatry, 57(Suppl 2), S216S221. doi:10.4103/0019-5545.161481

- Shaikh, H. (2016). Housing inequality in Pakistan. International Growth Centre; Ideas for Growth, http://cdpr.org.pk/wpcontent/uploads/2016/02/IGC-Pakistan2016-Policy-note.pdf.

- Shamoon Noushad, \& Ahmed, S. (2013). Novel stress evaluating tool; Sadaf Stress Scale (SSS), tested on so far on Pakistani Population. International Journal of Endorsing Health Science Research, 1(2), 57-61.

- Stiffler, D., Cullen, D., Stephenson, E., Luna, G., \& Hartman, T. D. (2016). When Baby Stops Breathing: Analysis of Mothers' Interviews. Clinical Nursing Research, 25(3), 310-324. doi:10.1177/1054773815619580

- Turton, P., Hughes, P., Evans, C. D. H., \& Fainman, D. (2001). Incidence, correlates and predictors of posttraumatic stress disorder in the pregnancy after stillbirth. The British Journal of Psychiatry, 178(6), 556-560. doi:10.1192/bjp.178.6.556

- UNICEF-Report-2015. Level and Trend in Child Mortality; Report 2015. http://www.childmortality.org/files_v20/ download/IGME\%20Report\%202015_9_ 3\%20LR\%20Web.pdf.

- Uzma Afzal, A. Y. (2013). The State of Health in Pakistan: An Overview. The Lahore Journal of Economics, 18, 233247. 